\title{
Double-blind trial of propranolol and practolol in hypertrophic cardiomyopathy
}

\author{
P. J. B. Hubner, Galal M. Ziady, G. K. Lane, T. Hardarson, B. Scales, C. M. Oakley, and \\ J. F. Goodwin \\ From the Division of Cardiovascular Disease (Clinical Cardiology), Royal Postgraduate Medical School, \\ Hammersmith Hospital, London
}

Propranolol (320 mg/day), practolol ( $800 \mathrm{mg} /$ day), and placebo were each administered for 4 weeks in a double-blind manner to I6 patients with hypertrophic cardiomyopathy. Symptoms were assessed using a diary card and a scoring method. Clinical examination and non-invasive tests (phonocardiography and apex cardiography) were also performed.

Dyspnoea was improved only in patients with severe limitation (NYHA Class III), the result being significant $(P=0.03)$ for propranolol but not for practolol. Angina became less frequent with both drugs, the result being significant with propranolol $(P=0.03)$ but not with practolol. Palpitation was significantly reduced $(P<0.01)$ with propranolol, but not with practolol. Left ventricular ejection time index was significantly prolonged with propranolol $(P=0.006)$ but not with practolol. Both drugs significantly reduced the ' $A$ ' wave $(P<0.01$ ), and the isovolumic relaxation time (propranolol, $P=0.01$, practolol, $P=0.04$ ) of the apex cardiogram. The $Q-A 2$ interval, the pre-ejection period, and rapid filling wave were unchanged as were clinical findings except for a significant $(P<0 \cdot 01)$ reduction of heart rate with propranolol.

The results are compatible with increased left ventricular compliance, a desirable effect even in patients whose symptoms are mild or absent. For patients with severe dyspnoea, angina, or palpitation symptomatic improvement is likely with these drugs. With the dosages used propranolol has been found to be superior to practolol.

Though beta-adrenergic blocking drugs have been used for several years in the treatment of patients with hypertrophic cardiomyopathy, there is still disagreement as to their value and place in management. Some authors suggest that they should be given to all patients even those who are asymptomatic (Goodwin and Oakley, 1972), while others suggest that they should be reserved only for patients who have not responded to cardiac operation (Rookmaker et al., 197I). Though earlier reports were enthusiastic about the relief of symptoms (Cherian et al., 1966; Sloman, 1967), it was later suggested that dyspnoea, in particular, was poorly relieved (Goodwin, 1970).

One of the difficulties in interpreting the value of these drugs has been the lack of objective assessment of the results of oral treatment. To our knowledge there has been only one controlled assessment of symptoms, that of Cohen and Braunwald (1967), who showed in a single-blind trial that $80-480 \mathrm{mg}$ Received 18 June 1973. propranolol reduced angina after treadmill exercise. The haemodynamic findings after six months of treatment with 120 to $160 \mathrm{mg}$ propranolol showed no significant change in 7 patients reported by Rookmaker et al. (197I).

Besides propranolol, practolol has also been given to patients with hypertrophic cardiomyopathy (Webb-Peploe et al., 1971; Goodwin and Oakley, 1972; Matlof and Harrison, 1973). This drug is relatively cardiospecific and has little action on beta-receptors of peripheral blood vessels or bronchi; it also has a weak intrinsic sympathomimetic action (Barrett, 197I). These features suggest that practolol might have different effects from propranolol in hypertrophic cardiomyopathy, and in acute studies it has been found to have little or no effect on the left ventricular outflow tract gradient (Webb-Peploe et al., I97I; Matlof and Harrison, 1973).

This paper reports the results of a double-blind crossover trial of the symptomatic responses after 
oral administration of propranolol, practolol, and placebo. As symptomatic assessment is dependent upon subjective observations made by patients, physical examination and noninvasive techniques were also used to determine whether any evidence of haemodynamic improvement could be shown.

\section{Methods}

Sixteen patients took part in the trial which was conducted from January to April 197I. There were II women and 5 men, and their ages ranged from 21 to 58 (mean 36 ) years. There was a family history of the disorder in 3 , and a possible history in a further 3 patients. The diagnosis of hypertrophic cardiomyopathy had been confirmed in all patients by cardiac catheterization and left ventricular angiography which had been performed I month to 6 years Io months (mean 3 years Io months) before the start of the trial. The left ventricular enddiastolic pressure at rest was raised in all patients except 2 and ranged from to to 26 (mean 18.5 ) $\mathrm{mmHg}$. In one patient a left ventricular outflow gradient was absent at rest and also after stimulation by isoprenaline. In the remaining patients the gradient ranged from 0 to IIS (mean 60) $\mathrm{mmHg}$ at rest, and from 50 to 140 (mean 88) $\mathrm{mmHg}$ after stimulation with isoprenaline. No patient had had previous cardiac operation, and none had any other known disorder. In particular no patient had rheumatic or congenital heart disease or airways obstruction.

All except 2 patients had been taking either propranolol or practolol before the start of the trial. Apart from trinitrin (4 patients) and an oral contraceptive preparation ( 2 further patients) no other drugs were being taken before or during the trial.

Two patients not described above started the trial but were withdrawn, one because of previously unrecognized obstructive airways disease exacerbated by propranolol, and the other because of inability to take the tablets correctly and to comply with the other methods used in the trial.
The patients were asked if they would co-operate in a clinical trial to assess the treatment of their condition. It was explained that three drugs would be compared. They were not informed that one of these would be a placebo, but they were told that one of the drugs would be the same as that which they were already receiving.

Propranolol ( $320 \mathrm{mg} /$ day), practolol $(800 \mathrm{mg} /$ day), and the placebo were supplied by ICI Ltd. Each preparation was administered daily for 4 weeks in a randomized double-blind manner, and each consisted of tablets of an identical size, colour (yellow), and appearance. One tablet was taken orally at breakfast, lunchtime (or midday), at teatime (late afternoon), and before retiring to bed. A 4-week supply of tablets was given in a small bottle which the patients were asked to carry with them throughout the day. At the next visit the bottle was returned and any unused tablets counted. A blood sample was taken at the end of each visit and later analysed for active drug.

\section{Methods of assessment}

At an initial visit the methods to be used in the trial were explained; a physical examination, and the noninvasive procedures to be used at subsequent visits were performed to accustom the patient to them.

I) Symptoms These were assessed using a diary card record. An example is shown in Table I. For dyspnoea, patients recorded at the end of the day whether their breathing on exertion had been satisfactory (i.e. the same as usual), less good than usual (bad day), or better than usual (good day). The total number of episodes of angina and blackouts (syncope) were also recorded. To allow for the crossover period between 2 treatment months, the results of the first 4 days and the last 3 days of each 4-week period were not used in the analysis of the diary cards. At each visit inquiry was made into the patients' assessment of the frequency during the month of dizziness, palpitation, wheezing, gastrointestinal symptoms, headache, and any other symptom that had been noted. A score of 3, 2, 1 , or 0 was given if the

TABLE I Example of a page from a diary card record

\begin{tabular}{|c|c|c|c|c|c|}
\hline \multirow[b]{2}{*}{ Day } & \multirow[b]{2}{*}{ Date } & \multicolumn{3}{|c|}{ Breathing $\star$} & \multirow{2}{*}{$\begin{array}{l}\text { Chest pain Blackouts } \\
\begin{array}{l}\text { Number of episodes } \\
\text { - if any }\end{array}\end{array}$} \\
\hline & & $\begin{array}{l}\text { Less good } \\
\text { than usual } \\
\text { (bad day) }\end{array}$ & Satisfactory & $\begin{array}{l}\text { Better than } \\
\text { usual } \\
\text { (good day) }\end{array}$ & \\
\hline Monday & $8.3 .7 \mathrm{I}$ & & & $\checkmark$ & \\
\hline Tuesday & $9.3 .7 I$ & $\checkmark$ & & & 3 \\
\hline Wednesday & 10.3 .71 & $\checkmark$ & & & $\mathrm{r}$ \\
\hline Thursday & II.3.7 I & & $\checkmark$ & & \\
\hline Friday & $12.3 .7 \mathrm{I}$ & & $\checkmark$ & & \\
\hline Saturday & 13.3 .71 & & $\checkmark$ & & \\
\hline Sunday & 14.3 .71 & & $\checkmark$ & & \\
\hline
\end{tabular}

Breathing ${ }^{\star}$ refers to any shortness of breath noted on exercise or exertion, e.g. walking, climbing stairs. Please fill in this table, when taking the last tablet of the day. 
symptom occurred frequently, occasionally, rarely, or not at all, respectively.

2) Physical examination This was performed throughout by one operator who was unaware of the symptomatic course during the previous month. It included the pulse, supine and erect blood pressure, jugular venous pressure, form of apical impulse, and auscultation of the heart and lungs. The intensity of the systolic murmur was scored o to 4 .

3) Non-invasive techniques These were recorded by operators who were also unaware of the symptomatic course, using a 6-channel Cambridge machine (model 72112 ; Cambridge Scientific Instruments). The sensitivity settings of the initial visit were used throughout the trial. Phonocardiograms were recorded at the second and fourth intercostal spaces along the left sternal border and at the apex using suction microphones with high $(450-1000 \mathrm{~Hz})$ and low $(250-1000 \mathrm{~Hz})$ frequency filters. A bipolar electrocardiograph lead showing clearly the onset of ventricular depolarization was recorded simultaneously.

The apex cardiogram was obtained in the left lateral position except for 2 patients in whom the cardiac impulse was too strong, when the supine position was used. The carotid pulse and apex cardiogram were obtained with a hand-held polyethylene funnel connected to a piezoelectric transducer with a pulse amplifier of time constant $\mathrm{I} \cdot 6 \mathrm{sec}$, filter $0 . \mathrm{I}$ to $100 \mathrm{~Hz}$.
The phonocardiogram was analysed for the presence or absence of systolic murmur, third or fourth heart sounds ( $\mathrm{S}_{3}$ and $\mathrm{S}_{4}$ ), and behaviour of the second heart sound $\left(\mathrm{S}_{2}\right)$ with respiration. Systolic time intervals were analysed for left ventricular ejection time (LVET), measured from the onset of the steep carotid upstroke to the dicrotic notch, total electromechanical systole (Q-A2) from the beginning of the $Q$ wave of the electrocardiogram to the aortic component of $S_{2}$, and the preejection period (PEP) calculated as Q-A2 - LVET. All the intervals were calculated to the nearest $5 \mathrm{msec}$. The intervals were corrected for the heart rate (Weissler, Harris, and Schoenfeld, 1969), and subsequent discussion refers to these corrected values.

The apex cardiogram was analysed for the ' $A$ ' wave and the rapid filling wave as percentages of the total amplitude of the curve (Benchimol and Dimond, 1963); the isovolumic relaxation time was measured from $A_{2}$ of the phonocardiogram to the ' $O$ ' point of the apex cardiogram (Benchimol and Ellis, 1967).

Statistical analysis of the diary card results was made using a non-parametric test; a paired student t-test was used for the other analyses.

\section{Results}

Dyspnoea (Tables 2 and 3)

For this symptom patients were subdivided by the New York Heart Association (NYHA) classifica-

TABLE 2 Dyspnoea results

\begin{tabular}{|c|c|c|c|c|c|c|c|c|c|c|}
\hline \multirow{2}{*}{$\begin{array}{l}\text { NYHA } \\
\text { class }\end{array}$} & \multirow{2}{*}{$\begin{array}{l}\text { No. of } \\
\text { patients }\end{array}$} & \multicolumn{3}{|l|}{ Placebo } & \multicolumn{3}{|c|}{ Propranolol } & \multicolumn{3}{|c|}{ Practolol } \\
\hline & & $D>U$ & $D=U$ & $D<U$ & $D>U$ & $D=U$ & $D<U$ & $D>U$ & $D=U$ & $D<U$ \\
\hline I & 2 & 2 & 19 & 0 & 0 & $2 \mathbf{I}$ & o & $\mathbf{I}$ & 20 & 0 \\
\hline II & 9 & 4.5 & 149 & $I \cdot 6$ & $3 \cdot 4$ & 15.5 & $2 \cdot 1$ & & 15.4 & $I \cdot 6$ \\
\hline III & 5 & $14 \cdot 4$ & $5 \cdot 2$ & $I \cdot 4$ & $4^{\cdot 8^{\star}}$ & $10 \cdot 2$ & 6 & $4 \cdot 6^{\star \star}$ & II. 4 & 5 \\
\hline
\end{tabular}

$P$ (drug v. placebo) $=0.03^{\star}$ and 0.18 (NS) ${ }^{\star \star}$.

For each preparation the mean number of days spent by the patients in the categories dyspnoea more than usual $(D>U)$,

the same as usual $(D=U)$,

or less than usual $(D<U)$ are shown.

TABLE 3 Dyspnoea results: patients from NYHA class III

\begin{tabular}{|c|c|c|c|c|c|c|c|c|c|}
\hline \multirow{2}{*}{$\begin{array}{l}\text { Patient } \\
\text { trial no. }\end{array}$} & \multicolumn{3}{|l|}{ Placebo } & \multicolumn{3}{|c|}{ Propranolol } & \multicolumn{3}{|c|}{ Practolol } \\
\hline & $D>U$ & $D=U$ & $D<U$ & $D>U$ & $D=U$ & $D<U$ & $D>U$ & $D=U$ & $D<U$ \\
\hline 3 & 17 & 4 & 0 & 2 & 9 & ro & 2 & 13 & 6 \\
\hline 5 & 14 & 7 & 0 & 5 & 16 & 0 & 3 & 18 & 0 \\
\hline 7 & 9 & 12 & 0 & 8 & 7 & 6 & I & 10 & Io \\
\hline 12 & 12 & 2 & 7 & 7 & Io & 4 & 13 & 6 & 2 \\
\hline I4 & 20 & I & 0 & 2 & 9 & IO & 4 & IO & 7 \\
\hline Mean & $14 \cdot 4$ & $5 \cdot 2$ & $I \cdot 4$ & $4^{\cdot 8 \star}$ & 10.2 & 6 & $4^{\cdot 6 \star \star}$ & I I 4 & 5 \\
\hline
\end{tabular}

$P$ (drug v. placebo) $=0.03^{\star}$ and $0.18(\mathrm{NS})^{\star \star}$.

Abbreviations as in Table 2. 
tion into class I, with 2 patients; class II, with 9 patients; and class III, with 5 patients. There were no differences between the results of the three preparations in patients of classes I and II. For class III patients, the average number of days recorded as dyspnoea more than usual was reduced with beta-blocking drugs from 14.4 days with placebo to 4.8 and 4.6 days with propranolol and practolol, respectively. Similarly, there was also a small increase in the average number of days recorded as

TABLE 4 Angina: number of episodes of angina over 21 days with each preparation

\begin{tabular}{lcll}
\hline & \multicolumn{3}{l}{ No. of episodes of angina } \\
\cline { 2 - 4 } $\begin{array}{l}\text { Patient } \\
\text { trial no. }\end{array}$ & Placebo & Propranolol & Practolol \\
\hline 3 & 19 & 2 & 7 \\
6 & 17 & 6 & 3 \\
13 & 3 & 3 & 5 \\
14 & 21 & 0 & 0 \\
16 & 315 & 0 & 72 \\
& & $P=0.03$ & $P=0.18(N S)$
\end{tabular}

( $\mathrm{P}=$ drug v. placebo). dyspnoea less than usual. On statistical analysis of this small number of patients (5) in class III, the reduction of the number of days recorded as dyspnoea more than usual with propranolol was the only significant result $(P=0.03)$ (Table 2$)$.

\section{Angina (Table 4)}

Of the 5 patients with angina, I was in the dyspnoea class I and 2 were in each of the dyspnoea classes II and III. In 4 patients the number of anginal episodes was reduced, on propranolol and practolol. The reduction was greater with propranolol and was statistically significant $(P=0.03)$. The fifth patient with infrequent angina had marginally more episodes on practolol than placebo, and the results with practolol were not significant.

\section{Other symptoms (Table 5)}

Only two syncopal episodes occurred throughout the trial, one during the placebo period, and the second with another patient while on practolol. The score for the frequency of palpitation was significantly reduced with propranolol $(\mathbf{P}<0.01)$; a smaller nonsignificant reduction occurred with practolol. There

TABLE 5 Other symptoms

\begin{tabular}{|c|c|c|c|c|c|c|}
\hline \multirow{2}{*}{ Symptom } & \multicolumn{2}{|c|}{ Placebo } & \multicolumn{2}{|c|}{ Propranolol } & \multicolumn{2}{|c|}{ Practolol } \\
\hline & $\begin{array}{l}\text { No. of } \\
\text { patients }\end{array}$ & Score & $\begin{array}{l}\text { No. of } \\
\text { patients }\end{array}$ & Score & $\begin{array}{l}\text { No. of } \\
\text { patients }\end{array}$ & Score \\
\hline Syncopal episode & $\mathbf{I}$ & - & 一 & 一 & $\mathbf{I}$ & 一 \\
\hline Palpitation & 8 & 14 & 4 & $6^{\star}$ & 6 & I I \\
\hline Dizziness & 6 & IO & 4 & 6 & 8 & 9 \\
\hline Headaches & Io & 14 & 6 & 8 & 6 & 10 \\
\hline Gastrointestinal symptoms & 2 & 2 & 4 & 4 & $\mathbf{I}$ & $\mathbf{I}$ \\
\hline Wheezing & 2 & 2 & 2 & 2 & 2 & 2 \\
\hline
\end{tabular}

$\star P$ (drug v. placebo) $<0.01$.

Score refers to total value from all the patients' assessments of the frequency of the symptom. For scoring methods see text.

TABLE 6 Findings of physical and phonocardiographic examinations

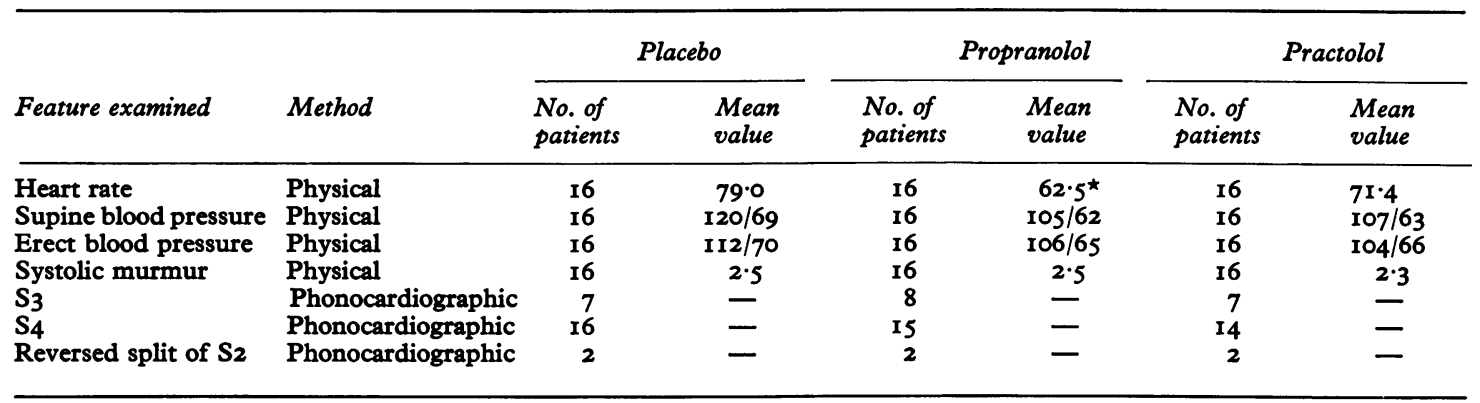

* $\mathbf{P}$ (drug v. placebo) <0.01.

Intensity of systolic murmur scored $\circ$ to 4 by auscultation. 
were no significant differences between the preparations for the scores of dizziness, headaches, wheezing, or gastrointestinal symptoms (abdominal pain with 2 patients, diarrhoea with 2 patients, constipation with I patient). On placebo I patient had an epistaxis, on practolol I patient noted a rash which cleared before he was seen in the clinic, and another patient noted excess sweating.

Physical and phonocardiographic examinations (Table 6)

The resting heart rate was significantly reduced $(\mathbf{P}<0.01)$ with propranolol; a smaller non-significant fall occurred with practolol. There were no statistical differences between the preparations in their effect on supine and erect blood pressure, or the intensity of the systolic murmur. The jugular venous pressure and auscultation of the lungs were normal, and the form of apical impulse was unchanged throughout the trial. The phonocardiogram revealed a fourth heart sound in all 16 patients, a third heart sound in 8 patients, and reversed splitting of the second heart sound in 2 patients. There were no significant differences between the preparations in the incidence of these features.

\section{Systolic time intervals (Table 7)}

All the patients had prolonged intervals with each of the preparations; when they were taking placebo, the statistical significances of the prolongations were
Q-A2 $(\mathbf{P}=0.00 \mathrm{I})$, LVET $(\mathbf{P}=0.0 \mathrm{I})$, and PEP $(P=0.04)$ compared with the normal values of this laboratory derived from the records of 24 normal subjects. On propranolol, the LVET was significantly longer than with the placebo $(P=0.006)$. There was no statistical difference between LVET on practolol and on the placebo; nor were there any significant differences between the preparations for Q-A2 and PEP.

\section{Apex cardiogram (Table 8)}

The ' $A$ ' wave was abnormally large in 15 out of the I6 patients and was significantly reduced with both propranolol and practolol $(\mathrm{P}<0 \cdot 0 \mathrm{I})$. The rapid filling wave was within normal range in all patients and no significant change occurred with either drug. The isovolumic relaxation time was abnormally prolonged in all patients while on the placebo, compared with the values for 13 normal subjects $(P=0.00 I)$. It was significantly shortened with both propranolol $(\mathbf{P}=0.0 \mathrm{I})$ and practolol $(\mathbf{P}=0.04)$.

\section{Drug administration}

The number of unused tablets was higher (but not significantly so) with propranolol (mean 5.2, range O-I6) than with the placebo (mean $2 \cdot 9$, range o-10) or practolol (mean 3.I, range $0-15$ ). The maximum number of unused tablets was 16 out of I 12 tablets or 4 out of 28 days' supply. The mean blood level

TABLE 7 Systolic time intervals: Mean values \pm standard error of mean in msec in trial patients and 24 normal subjects

\begin{tabular}{lllll}
\hline \multirow{2}{*}{ Feature } & & \multicolumn{3}{l}{ Hypertrophic cardiomyopathy trial patients } \\
\cline { 2 - 5 } & $\begin{array}{l}\text { Normal } \\
\text { values }\end{array}$ & Placebo & Propranolol & Practolol \\
\hline Q-A & $526 \cdot 3( \pm 3 \cdot 3)$ & $559 \cdot 6( \pm 7 \cdot 8)$ & $569 \cdot 1( \pm 8 \cdot 2)$ & $554 \cdot 9( \pm 8 \cdot 8)$ \\
$\begin{array}{l}\text { Left ventricular ejection time } \\
\text { Pre-ejection period }\end{array}$ & $\begin{array}{l}409 \cdot 7( \pm 2 \cdot 8) \\
\text { I16.7( } \pm 2 \cdot 2)\end{array}$ & $\begin{array}{l}431 \cdot 5( \pm 9 \cdot 0) \\
127 \cdot 4( \pm 5 \cdot 5)\end{array}$ & $\begin{array}{l}454 \cdot 3( \pm 9 \cdot 5)^{\star} \\
122 \cdot 1( \pm 5 \cdot 1)\end{array}$ & $\begin{array}{l}428 \cdot 4( \pm 10 \cdot 2) \\
126 \cdot 1( \pm 5 \cdot 7)\end{array}$ \\
\hline
\end{tabular}

$P$ (drug v. placebo) $=0.006^{\star}$.

TABLE 8 Apex cardiogram: mean values \pm standard error of mean

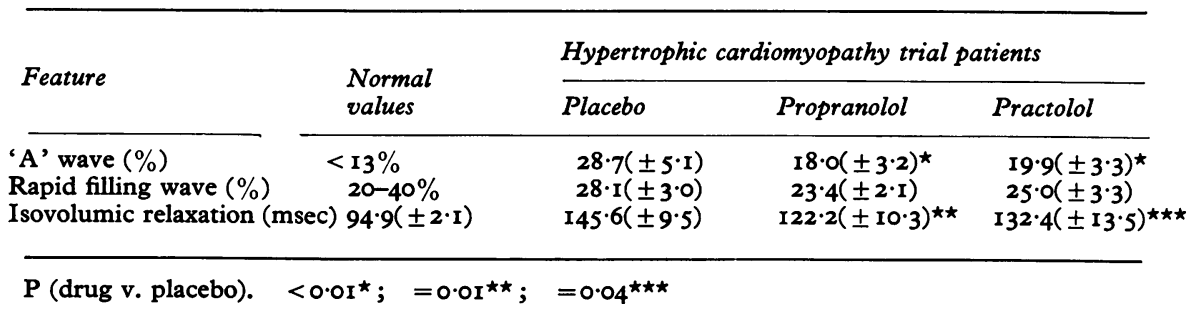


with propranolol was $0.1 \mathrm{I}$, range $0.0 \mathrm{I}$ to $0.28 \mu \mathrm{g} / \mathrm{ml}$, and for practolol was 4.9 , range $2 \cdot 80-8 \cdot 80 \mu \mathrm{g} / \mathrm{ml}$.

\section{Discussion}

This trial was designed to determine whether any objective or symptomatic improvement with propranolol or practolol could be demonstrated in patients with hypertrophic cardiomyopathy. Evaluation of therapy to reduce dyspnoea is hindered by the difficulty in assessing this symptom, the severity of which can vary widely in patients with identical haemodynamic disturbances. While most methods of dyspnoea assessment are open to criticism, the diary cards did allow a daily record of its severity; reports over a longer period may be unduly influenced by severity over the few days preceding assessment.

No overall improvement or deterioration of dyspnoea was shown for asymptomatic patients (class I NYHA) or those with mild dyspnoea (class II NYHA). For the patients with more severe dyspnoea in class III, all while on propranolol and 4 out of the 5 also while on practolol showed improvement over the placebo period by a reduction in the number of days recorded as dyspnoea more than usual (Tables 2 and 3 ). This reduction was significant with propranolol $(P=0.03)$ but not with practolol. There was also a smaller nonsignificant increase with both drugs of the number of days recorded as dyspnoea less than usual. These findings suggest that patients with more severe dyspnoea are the ones likely to notice improvement with the drugs. This result, however, could merely reflect that when dyspnoea is severe an improvement is more readily appreciated.

There were no significant differences between the patients of class III who improved with the drugs and the remainder of the patients, in the type or severity of left ventricular outflow obstruction or left ventricular end-diastolic pressure. Hence no support is given to the view (Flamm, Harrison, and Hancock, 1968; Adelman et al., 1970) that patients with latent obstruction (gradient absent at rest appearing on stimulation), or very labile obstruction, are more likely to respond to beta-blocking drugs than those where the obstruction is relatively more constant. However, the haemodynamic data on these patients had been obtained at a mean of just under 4 years previously and could have altered since then. But it is also doubtful whether patients with hypertrophic cardiomyopathy can be subdivided by the left ventricular outflow gradient which is characteristically labile and which can vary in severity and form during an investigation or between consecutive ones.
Propranolol and practolol are well established in the treatment of angina due to coronary artery disease (Gillam and Pritchard, 1965; Grant et al., 1966; Sandler and Clayton, 1970; George, Nagle, and Pentecost, 1970). In hypertrophic cardiomyopathy, angina has usually been ameliorated by propranolol (Sloman, 1967; Cohen and Braunwald, 1967; Goodwin, 1970), and this was confirmed in this trial where with 4 out of 5 patients this symptom was reduced in frequency (Table 4). This reduction was significant for propranolol $(\mathbf{P}=0.03)$. Practolol was less effective in all patients and the results were not significant.

Effort syncope was too infrequent to assess the value of the drugs, as only two episodes occurred throughout the trial. Palpitation was found to be significantly reduced $(\mathrm{P}<0.0 \mathrm{I})$ with propranolol (Table 5) as has previously been reported (Bliss, Moffat, and Gantt, 1967; Adelman et al., 1970). A smaller non-significant reduction for palpitation also occurred with practolol. Both the drugs have potent antiarrhythmic actions and might therefore be expected to reduce frequency and duration of arrhythmias. One patient with documented paroxysmal atrial fibrillation had episodes that were shorter and less frequent while on the drugs. However, as documented paroxysmal tachyarrhythmias are not common in hypertrophic cardiomyopathy, palpitation and its relief are unlikely to be solely due to arrhythmias and their suppression. In some patients palpitation represents an awareness of the normal heart beat which may become less noticeable if the heart rate is slowed. Hence propranolol may have been more effective than practolol because it produced a greater reduction of heart rate (Table 6).

There was no statistical difference between the preparations in the frequency of dizziness, headaches, gastrointestinal symptoms, or wheezing. The last three symptoms were assessed to detect any possible side effects which were not found.

Apart from a reduction of resting heart rate which was significant $(\mathbf{P}<0.01)$ with propranolol but not with practolol, clinical examination did not reveal any differences between the three preparations. These results agree with earlier reports (Goodwin, I970; Adelman et al., 1970) that usually betablocking drugs administered orally do not reduce the intensity of the systolic murmur and they probably therefore have little or no effect on the outflow tract gradient.

The noninvasive procedures were undertaken to determine whether these indices of cardiac function might indicate any evidence of, or mechanism for haemodynamic improvement. The left ventricular ejection time was abnormally prolonged, and after 
propranolol there was a further significant $(\mathbf{P}=$ 0.006 ) increase (Table 7). There was no statistical difference between left ventricular ejection time on practolol or on placebo. Its prolongation in aortic valvar stenosis is related to the outflow gradient (Benchimol, Dimond, and Shen, 1960) and this has also been confirmed in hypertrophic cardiomyopathy (T. Hardarson, 1972, unpublished results). However, the further prolongation of left ventricular ejection time after propranolol is very unlikely to be due to increased left ventricular outflow obstruction, as propranolol usually reduces the gradient or leaves it unchanged (Flamm et al., 1968; Goodwin, 1970). Alternative explanations for the further prolongation of left ventricular ejection time include reduced rate of ejection due to reduced contractility, or an increase in stroke volume resulting from increased ventricular filling due to increased compliance of the left ventricle. The preejection period and $\mathrm{Q}-\mathrm{A}_{2}$ did not alter significantly with either preparation.

The ' $A$ ' wave of the apex cardiogram was abnormally large (Table 8 ) as had previously been recorded in hypertrophic cardiomyopathy (Wolfe, 1966; Epstein et al., 1968). It was significantly $(P<0.01)$ reduced by both propranolol and practolol. The ' $A$ ' wave of the apex cardiogram is closely related to the ' $a$ ' wave of the left atrial record and usually reflects left ventricular end-diastolic pressure (Voigt and Friesinger, 1970), so that a reduction of the ' $A$ ' wave suggests that the enddiastolic pressure was lowered by the drugs. The pressure could fall as a result of reduced resistance to ventricular filling, i.e. increased ventricular compliance, or because of less powerful atrial contraction. The latter mechanism has been implicated in the reduction of ' $A$ ' wave of the apex cardiogram in aortic valve stenosis after propranolol (Hamer and Fleming, 1967). Increase in ventricular compliance is supported by the significant shortening of the isovolumic relaxation time after both propranolol and practolol. This interval, which was prolonged in the patients, is related to aortic diastolic pressure, and inversely to rate of ventricular relaxation and heart rate (Benchimol and Ellis, 1967). With the slowing of the heart rate produced by the drugs, an increase in the isovolumic relaxation time might have been expected. As only a small nonsignificant change in diastolic blood pressure was found, the shortening of this interval suggests an increased rate of relaxation of the left ventricle, which is again compatible with increased ventricular compliance.

The values for the rapid filling wave were within the normal range and were not significantly altered by the drugs. The normal values were probably due to the balanced effects of left ventricular outflow and inflow obstruction reducing the rapid filling wave, and mitral regurgitation increasing the rapid filling wave. Similarly with the drugs the rapid filling wave would tend to be increased with increased ventricular compliance, but to be decreased if mitral regurgitation were reduced.

Three of the noninvasive parameters studied, left ventricular ejection time, ' $A$ ' wave, and isovolumic relaxation time of the apex cardiogram, altered with drugs, and the changes in each case were compatible with an increase in ventricular compliance. This explanation is in agreement with the observations from acute studies with practolol in hypertrophic cardiomyopathy (Webb-Peploe et al., 197I), when the possibility of increased ventricular compliance was also suggested. In summary, the results of the non-invasive tests are compatible with the concept of beta-adrenergic blockade mainly affecting ventricular compliance in hypertrophic cardiomyopathy.

The design and methods of the trial were described in some detail to satisfy the suggested requirements for the interpretation of a clinical trial (Lionel and Herxheimer, 1970). It is important to ascertain that the drugs studied were in fact taken by the patients. This was attempted by two methods, determining the number of unused tablets, and by measuring the drug blood level. Out of the initial 112 issued, only a small number of tablets were returned unused, mean $2.9,5.2$, and 3.1 for placebo, propranolol, and practolol, respectively. The number of tablets for propranolol was not significantly higher than the two other preparations, and it was propranolol that was found to be the more effective drug. The drug blood levels also suggested that the tablets were being taken. One patient, who was withdrawn from the trial because of difficulty in complying with the methods, had no assayable practolol in the blood at one visit. The mean propranolol blood level (0.1I $\mu \mathrm{g} / \mathrm{ml})$ was in the range known to be associated with beta-blockade (Coltart and Shand, 1970). The blood levels varied less with practolol than with propranolol, reflecting inter alia the longer biological half-life of practolol. The reduction of heart rate with the drugs, which was significant with propranolol $(\mathrm{P}<0.0 \mathrm{I})$, also confirms that the drugs were being taken at least on the day of assessment.

All the actions, including the effects on both symptoms and noninvasive tests, were greater with propranolol, so that in the doses used in this trial, propranolol was found to be more effective than practolol. This result may reflect differences between effects of these drugs other than their betablocking action, or that the doses selected were 
not comparable in beta-blocking effect. Betablocking drugs exhibit competitive inhibition with catecholamines, so that the degree of blockade is dependent on dosage (Dollery, Paterson, and Conolly, 1969). Hence, it is possible that, had larger doses of practolol been used, comparable results to those of propranolol might have been obtained. However, in acute studies practolol has been found to be less successful than propranolol in preventing outflow tract gradients in hypertrophic cardiomyopathy (Webb-Peploe et al., 1971; Matlof and Harrison, 1973), and in the management of angina due to coronary artery disease propranolol appears to be more successful than practolol (Sandler and Clayton, I970; George et al., 1970). Thus, for patients with hypertrophic cardiomyopathy it is suggested that treatment be started with propranolol, unless there is a history of obstructive airways disease when practolol would be preferable.

This trial was not designed to determine whether the drugs improved the long-term prognosis of this disorder. Similarly episodes of effort syncope were too infrequent for the value of drugs to be assessed. The subjective effect of the drugs could have been minimized by the high proportion of patients in the trial who had mild or no symptoms. However, the results of the noninvasive tests used suggested that even patients with few or no symptoms sustained some haemodynamic improvement. These findings therefore support the view of Goodwin and Oakley (1972) that even asymptomatic patients may benefit from beta-blocking drugs. Patients with only mild or moderate dyspnoea may notice no change, but for patients with severe dyspnoea, angina, or troublesome palpitation this treatment is likely to produce symptomatic improvement.

We are grateful to Miss Aviva Petri for her assistance in statistical analysis, and to I.C.I. Limited, Great Britain.

\section{References}

Adelman, A. G., Shah, P. M., Gramiak, R., and Wigle, E. D. (1970). Long-term propranolol therapy in muscular subarotic stenosis. British Heart fournal, 32, 804.

Barrett, A. M. (1971). The pharmacology of practolol. Postgraduate Medical fournal, 47, Suppl. Jan., 7.

Benchimol, A., and Dimond, E. G. (1963). The normal and abnormal apex cardiogram. Its physiologic variation and its relation to intracardiac events. American fournal of Cardiology, 12, 368.

Benchimol, A., Dimond, E. G., and Shen, Y. (1960). Ejection time in aortic stenosis and mitral stenosis. American fournal of Cardiology, 5, 728.

Benchimol, A., and Ellis, J. G. (1967) A study of the period of isovolumic relaxation in normal subjects and in patients with heart disease. American fournal of Cardiology, 19, 196.

Bliss, H. A., Moffat, J. E., and Gantt, C. L. (1967). Effects of chronic oral propranolol therapy in idiopathic hypertrophic subaortic stenosis. Circulation, 35-36, Suppl. II, 72.

Cherian, G., Brockington, I. F., Shah, P. M., Oakley, C. M., and Goodwin, J. F. (1966). Beta-adrenergic blockade in hypertrophic obstructive cardiomyopathy. British Medical fournal, 1, 895.

Cohen, L. S., and Braunwald, E. (1967). Amelioration of angina pectoris in idiopathic hypertrophic subaortic stenosis with beta-adrenergic blockade. Circulation, 35, 847 .

Coltart, D. J., and Shand, D. G. (1970). Plasma propranolol levels in the quantitative assessment of beta-adrenergic blockade in man. British Medical fournal, 3, 731.

Dollery, C. T., Paterson, J. W., and Conolly, M. E. (1969). Clinical pharmacology of beta-receptor-blocking drugs. Clinical Pharmacology and Therapeutics, ro, 765.

Epstein, E. J., Coulshed, N., Brown, A. K., and Doukas, N. G. (1968). The ' $A$ ' wave of the apex cardiogram in aortic valve disease and cardiomyopathy. British Heart fournal, 30, 591.

Flamm, M. D., Harrison, D. C., and Hancock, E. W. (1968). Muscular subaortic stenosis. Prevention of outflow obstruction with propranolol. Circulation, 38, 846.

George, C. F., Nagle, R. E., and Pentecost, B. L. (1970). Practolol in treatment of angina pectoris. A double-blind trial. British Medical fournal, 2, 402.

Gillam, P. M. S., and Pritchard, B. N. C. (1965). Use of propranolol in angina pectoris. British Medical fournal, 2, 337.

Goodwin, J. F. (1970). Congestive and hypertrophic cardiomyopathies. A decade of study. Lancet, 1, 731.

Goodwin, J. F., and Oakley, C. M. (1972). The cardiomyopathies. British Heart fournal, 34, 545.

Grant, R. H. E., Keelan, P., Kernohan, R. J., Leonard, J. C., Nancekievill, L., and Sinclair, K. (I966). Multicenter trial of propranolol in angina pectoris. American fournal of Cardiology, 18, 36r.

Hamer, J., and Fleming, J. (1967). Effect of propranolol on left ventricular work in aortic stenosis. British Heart fournal, 29, 871 .

Lionel, N. D. W., and Herxheimer, A. (1970). Assessing reports of therapeutic trials. British Medical fournal, 3, 637 .

Matlof, H. J., and Harrison, D. C. (1973). Acute haemodynamic effects of practolol in patients with idiopathic hypertrophic subaortic stenosis. British Heart fournal, 35, 152.

Rookmaker, W. A., Nieveen, J., Kruizinga, K., and Blickman, J. R. (197I). Beta-adrenergic blockade in the treatment of left-sided hypertrophic obstructive cardiomyopathy (HOCM). Acta Medica Scandinavica, 189, 427.

Sandler, G., and Clayton, G. A. (1970). Clinical evaluation of practolol, a new cardioselective beta-blocking agent in angina pectoris. British Medical fournal, 2, 399.

Sloman, G. (1967). Propranolol in management of muscular subaortic stenosis. British Heart fournal, 29, 783.

Voigt, G. C., and Friesinger, G. C. (1970). The use of apex cardiography in the assessment of left ventricular diastolic pressure. Circulation, 4r, 1015.

Webb-Peploe, M. M., Croxson, R. S., Oakley, C. M., and Goodwin, J. F. (197I). Cardioselective beta-adrenergic blockade in hypertrophic obstructive cardiomyopathy. Postgraduate Medical fournal, 47, Suppl. Jan., 93.

Weissler, A. M., Harris, W. S., and Schoenfeld, C. D. (1969). Bedside technics for the evaluation of ventricular function in man. American fournal of Cardiology, 23, 577.

Wolfe, A. D. (1966). The A wave of the apex cardiogram in idiopathic hypertrophic subaortic stenosis. British Heart fournal, 28, 179.

Requests for reprints to Professor J. F. Goodwin, Division of Cardiovascular Disease (Clinical Cardiology), Royal Postgraduate Medical School, Hammersmith Hospital, Du Cane Road, London W.I2. 